Research Article

\title{
Hypolipidemic and antioxidant activities of pioglitazone in hyperlipidemic rats
}

\author{
Rama R. Bhosale*, Rakesh R. Jadhav, Sudhir L. Padwal, Vinod S. Deshmukh
}

Department of Pharmacology, Swami Ramanand Teerth Rural Hospital and Govt. Medical College, Ambajogai, DistrictBeed, Maharashtra 431517, India

Received: 10 December 2012 Accepted: 19 December 2012

*Correspondence to:

Dr. Rama R. Bhosale,

Email:

bhosale.rama@rediffmail.com

\begin{abstract}
Background: Diabetes mellitus (DM) is an endocrine disorder characterized by abnormal carbohydrate, lipid and protein metabolism along with specific long-term complications which are associated with hyperlipidemia and oxidative stress. Hence, it is important to find hypoglycemic drug that improves lipid profile and reduces oxidative stress in diabetic patient. This study, therefore, was performed to investigate hypolipidemic and antioxidant potential of Pioglitazone (PIO) in hyperlipidemic rats.

Methods: Hyperlipidemia was induced in normal rats by including $0.75 \mathrm{gm} \%$ cholesterol and $1.5 \mathrm{gm} \%$ bile salt in normal diet and these rats were used for the experiments. PIO hydrochloride was administered as $10 \mathrm{mg} / \mathrm{kg}$ and 30 $\mathrm{mg} / \mathrm{kg}$ dose levels to the hyperlipidemic rats. Hypolipidemic activity was estimated by plasma lipid profile parameters while antioxidant potential was estimated by ascorbic acid, catalase activity, malondialdehyde and superoxide dismutase activity using standard methods. Statistical analysis was done by one way analysis of variance (ANOVA) followed by Dunnett's test.

Results: Treatment with $10 \mathrm{mg} / \mathrm{kg}$ and $30 \mathrm{mg} / \mathrm{kg}$ dose levels of PIO hydrochloride resulted in a significant decrease in serum TG and VLDL only in $30 \mathrm{mg} / \mathrm{kg}$ PIO treated group and significant increase in serum HDL in both groups, but no significant decrease in cholesterol and LDL in both PIO treated groups. PIO increased activities of catalase enzyme and concentration of malondialdehyde significantly in only $30 \mathrm{mg} / \mathrm{kg}$ PIO treated group. But there were no significant changes in the superoxide dismutase activity and ascorbic acid concentration in both PIO treated groups.

Conclusions: The present study demonstrated that treatment with $10 \mathrm{mg} / \mathrm{kg}$ and $30 \mathrm{mg} / \mathrm{kg}$ dose levels of PIO hydrochloride improves the plasma lipid profile and also reduces oxidative stress in hyperlipidemic animals.
\end{abstract}

Keywords: Antioxidant, Diabetes, Hyperlipidemia, Pioglitazone

\section{INTRODUCTION}

Diabetes mellitus (DM) is a group of metabolic disorders characterized by hyperglycemia, abnormal lipid and protein metabolism along with specific long-term complications affecting the vital organs like nervous system, eye and kidney. ${ }^{1}$ Hyperglycemia in diabetic patients is associated with increase in lipid level and ultimately an increase in the atherogenic index. Therefore, DM is recognized as a major risk factor for cardiovascular diseases such as atherosclerosis and heart attack. $^{2}$ As diabetic patients have adverse changes related to their plasma lipid profile, it becomes very important to find an anti-diabetic agent that could improve lipid profile.

Free radical production has been reported to be increased in diabetic patients and increased glucose level appears to be the most important contributing factor for the generation of reactive oxygen species. These radicals deplete the activities of antioxidative defense systems with modification of activities of antioxidant enzymes such as superoxide dismutase, catalase and glutathione peroxidase. Increase in oxidative stress and changes in antioxidant capacity, induced by a high glucose, play a central role in complications of diabetes. ${ }^{3}$ Therefore, it is important to find hypoglycemic drug that reduces 
oxidative stress in diabetic patient. In short, an ideal oral treatment for diabetes would be a drug that not only controls the glucose level but also prevents the hyperlipidemia and other complications of diabetes by its antioxidant mechanism. Unfortunately, among the currently available anti-diabetic drugs, the choices are very limited.

The Thiazolidinediones drugs, a category of anti-diabetic medication, have emerged as an effective treatment option for improving glycemic control in patients with type-2 diabetes mellitus. This novel class of drugs acts as agonists for nuclear transcription factor peroxisome proliferators-activated receptor gamma (PPAR- $\gamma$ ) and primarily improve insulin sensitivity by enhancing the transcription of several insulin responsive genes. These drugs have been reported to improve parameters like plasma lipid profile and blood pressure which are very beneficial for the diabetic patients associated with cardiovascular diseases. The first generation drug, troglitazone, was withdrawn due to episodes of severe liver injury while the second-generation rosiglitazone and pioglitazone (PIO) showed no increased risk of hepatotoxicity. ${ }^{4}$

In past studies, PIO has inconsistent effects on lipid profile parameters. ${ }^{4-7}$ The objective of the present study was, therefore, to investigate exact effect of PIO on different lipid profile parameters and also its antioxidant effect in hyperlipidemic rats.

\section{METHODS}

\section{Animals}

All experiments and protocols described in present study were approved by the Institutional Animal Ethics Committee (IAEC). Male Albino rats weighing 200-250 gm were used for the experiment. They were kept on balanced diet and water ad libitum in a well-ventilated animal unit.

\section{Drugs}

Pioglitazone hydrochloride was obtained as a gift sample from Dr. Reddy's laboratories Ltd, India. Cholesterol and bile salt were purchased in pure powder form from Yucca Enterprises, Wadala (E) Mumbai, India. 0.75 gm\% cholesterol and $1.5 \mathrm{gm} \%$ bile salt of weight of total diet were used to produce hyperlipidemia in normal male albino rats. ${ }^{8}$ All other chemicals and reagents used in the present study were of analytical grade.

\section{Study design}

Study was conducted as follows:

After 10 days adaptation period, 24 animals were divided into four groups, each containing six animals $(n=6)$. The groups were treated as follows for four weeks:
Group I: Control group (Only standard diet was given).

Group II: Standard diet mixed with $0.75 \mathrm{gm} \%$ cholesterol and $1.5 \mathrm{gm} \%$ bile salt of the weight of the total diet to induce hyperlipidemia.

Group III: Standard diet mixed with $0.75 \mathrm{gm} \%$ cholesterol and $1.5 \mathrm{gm} \%$ bile salt to induce hyperlipidemia, along with Pioglitazone $(10 \mathrm{mg} / \mathrm{kg} / \mathrm{day}$ p.o. $)^{4}$ as suspension.

Group IV: Standard diet mixed with $0.75 \mathrm{gm} \%$ cholesterol and $1.5 \mathrm{gm} \%$ bile salt to induce hyperlipidemia along with Pioglitazone $(30 \mathrm{mg} / \mathrm{kg} / \mathrm{day}$ p.o. $)^{4}$ as suspension.

\section{Collection of blood samples}

On 30th day, after overnight fasting, blood was collected directly from heart of rat anaesthetized with ether. Abdomen was opened by taking a midline incision. Blood was sent to biochemistry laboratory in plain bulb; plasma was separated by centrifugation. Liver was excised and, both plasma and liver were kept frozen until analyzed.

\section{Biochemical analysis}

Plasma lipid profile was assessed by following parameters by standard methods: serum total cholesterol by Modified Roeschlau's Method, ${ }^{9}$ serum total triglycerides (TG) by method of Wako, modified by McGowan and Fossati, ${ }^{10}$ serum total high density lipoproteins (HDL) by Phosphotungstic Acid method, ${ }^{11}$ serum total low density lipoproteins (LDL) and serum total very low density lipoproteins (VLDL) by Friedewald formula. $^{12}$

Antioxidant potential was assessed by following parameters: Hepatic ascorbic acid by Schaffert RR et al method, ${ }^{13}$ catalase activity in liver by Cohen $G$ et al method, ${ }^{14}$ serum malondialdehyde (MDA) by Pasha and Sadasivadu method, ${ }^{15}$ serum superoxide dismutase activity (SOD) by Marklund and Marklund method. ${ }^{16}$

\section{Statistical Evaluation}

The results are expressed as means \pm SD (standard deviation). Significant differences among groups were determined by one way Analysis of variance (ANOVA). Dunnett's test was used for post hoc test analysis. Differences were considered significant if $p<0.05{ }^{17}$

\section{RESULTS}

\section{Plasma lipid profile}

PIO as $10 \mathrm{mg} / \mathrm{kg}$ and $30 \mathrm{mg} / \mathrm{kg}$ treatment to hyperlipidemic rats resulted in no significant decrease in total serum cholesterol and serum LDL-C as well. Serum 
HDL-C level increased significantly $(p<0.01)$ in both PIO treated groups (Table 1). These changes in HDL-C were dose dependent.

Table 1: Effect of pioglitazone on serum total cholesterol, serum LDL and serum HDL level in male albino rats.

\begin{tabular}{|lllll|}
\hline Groups $(\boldsymbol{n = 6})$ & $\begin{array}{l}\text { Treatment } \\
\text { given }\end{array}$ & $\begin{array}{l}\text { Sr. TC } \\
(\mathbf{m g} / \mathbf{d l})\end{array}$ & $\begin{array}{l}\text { Sr. LDL } \\
(\mathbf{m g} / \mathbf{d l})\end{array}$ & $\begin{array}{l}\text { Sr. HDL } \\
(\mathbf{m g} / \mathbf{d l})\end{array}$ \\
\hline Group I & Control & $127.12 \pm 6.51$ & $50.04 \pm 5.41$ & $66.78 \pm 2.24$ \\
\hline Group II & HL & $303.52 \pm 10.35$ & $250 \pm 11.27$ & $42.65 \pm 1.94$ \\
\hline Group III & HL+10P & $307.12 \pm 10.25 \mathrm{NS}$ & $248.19 \pm 15.82 \mathrm{NS}$ & $48.23 \pm 3.07^{*}$ \\
\hline Group IV & HL+30P & $304.48 \pm 9.36 \mathrm{NS}$ & $242.27 \pm 9.59 \mathrm{NS}$ & $53.12 \pm 3.93 * \#$ \\
\hline
\end{tabular}

(All values are Mean \pm Standard Deviation). $\mathrm{HL}=$ Hyperlipidemic group, $\mathrm{HL}+10 \mathrm{P}=$ Hyperlipidemic $+10 \mathrm{mg} / \mathrm{kg}$

Pioglitazone, HL+30P = Hyperlipidemic $+30 \mathrm{mg} / \mathrm{kg}$ Pioglitazone, TC $=$ Total Cholesterol, LDL = low density lipoproteins, HDL = high density lipoproteins, NS - Non-significant compared to Group II, * $p<0.01$ compared to Group II, \# $p<0.05$ compared to Group III (ANOVA followed by Dunnett's test).

Table 2: Effect of pioglitazone on serum TG and serum VLDL level in male albino rats.

\begin{tabular}{|llll|}
$\begin{array}{l}\text { Groups } \\
(\boldsymbol{n}=6)\end{array}$ & $\begin{array}{l}\text { Treatment } \\
\text { given }\end{array}$ & $\begin{array}{l}\text { Sr. TG } \\
(\mathbf{m g} / \mathbf{d l})\end{array}$ & $\begin{array}{l}\text { Sr. VLDL } \\
(\mathbf{m g} / \mathbf{d l})\end{array}$ \\
\hline Group I & Control & $51.53 \pm 2.75$ & $10.31 \pm 0.55$ \\
\hline Group II & HL & $54.29 \pm 3.28$ & $10.86 \pm 0.66$ \\
\hline Group III & HL+10P & $50.33 \pm 3.99 \mathrm{NS}$ & $10.06 \pm 0.78 \mathrm{NS}$ \\
\hline Group IV & HL+30P & $48.48 \pm 4.26^{*}$ & $9.70 \pm 0.85^{*}$ \\
\hline
\end{tabular}

(All values are Mean \pm Standard Deviation). $\mathrm{HL}=$ Hyperlipidemic group, $\mathrm{HL}+10 \mathrm{P}=$ Hyperlipidemic $+10 \mathrm{mg} / \mathrm{kg}$ Pioglitazone, HL+30P = Hyperlipidemic $30 \mathrm{mg} / \mathrm{kg}$ Pioglitazone, $\mathrm{TG}=$ Total triglycerides, VLDL = very low density lipoproteins, NS - Non-significant compared to Group II, * $p<0.05$ compared to Group II (ANOVA followed by Dunnett's test).

Table 3: Effect of pioglitazone on total ascorbic acid and activities of catalase in liver of male albino rats.

\begin{tabular}{|llll|}
\hline $\begin{array}{l}\text { Groups } \\
(\boldsymbol{n}=\mathbf{6})\end{array}$ & $\begin{array}{l}\text { Treatment } \\
\text { given }\end{array}$ & $\begin{array}{l}\text { Total ascorbic acid } \\
(\boldsymbol{\mu} / \mathrm{g})\end{array}$ & $\begin{array}{l}\text { Catalase } \mathrm{nm}^{\mathrm{H}} \mathrm{H}_{2} \mathrm{O}_{2} \\
\text { decomposed/sec/gm }\end{array}$ \\
\hline Group I & Control & $56.53 \pm 2.75$ & $20.31 \pm 0.55$ \\
\hline Group II & HL & $44.29 \pm 3.28$ & $13.86 \pm 0.66$ \\
\hline Group III & HL+10P & $44.93 \pm 3.89 \mathrm{NS}$ & $14.47 \pm 0.68 \mathrm{NS}$ \\
\hline Group IV & HL+30P & $46.48 \pm 4.36 \mathrm{NS}$ & $15.34 \pm 0.75^{*}$ \\
\hline
\end{tabular}

(All values are Mean \pm Standard Deviation). $\mathrm{HL}=$ Hyperlipidemic group, $\mathrm{HL}+10 \mathrm{P}=$ Hyperlipidemic $+10 \mathrm{mg} / \mathrm{kg}$ Pioglitazone, HL+30P = Hyperlipidemic+ $30 \mathrm{mg} / \mathrm{kg}$ Pioglitazone, NS - Non-significant compared to Group II, $* \mathrm{P}<0.05$ compared to Group II (ANOVA followed by Dunnett's test).

There were significant decrease in serum triglyceride $(p<0.05)$ and serum VLDL $(p<0.05)$ level with treatment of $30 \mathrm{mg} / \mathrm{kg}$ PIO treated group, but not with $10 \mathrm{mg} / \mathrm{kg}$ PIO treated group $(p=0.101)$. The values were decreased from $54.29 \pm 3.28 \mathrm{mg} \%$ to $48.48 \pm 4.26 \mathrm{mg} \%$ and from $10.86 \pm 0.66 \mathrm{mg} \%$ to $9.70 \pm 0.85 \mathrm{mg} \%$ in case of triglyceride and VLDL, respectively, in $30 \mathrm{mg} / \mathrm{kg}$ PIO treated group (Table 2).

\section{Antioxidant activities}

There was no significant increase in total ascorbic acid in liver in both PIO treated groups $(p=0.78$ and $p=0.35)$ i.e. group III and IV, respectively. Catalase activity in liver is increased significantly $(p<0.05)$ only in $30 \mathrm{mg} / \mathrm{kg}$ PIO treated group (Table 3). 
Table 4: Effect of pioglitazone on serum MDA and serum SOD level in male albino rats.

\begin{tabular}{|llll|}
$\begin{array}{l}\text { Groups } \\
(\boldsymbol{n}=\mathbf{6})\end{array}$ & $\begin{array}{l}\text { Treatment } \\
\text { given }\end{array}$ & $\begin{array}{l}\text { Sr. MDA } \\
(\mathrm{nmol} / \mathrm{ml})\end{array}$ & Sr. SOD $(\mathrm{U} / \mathrm{ml})$ \\
\hline Group I & Control & $1.41 \pm 0.27$ & $11.93 \pm 0.64$ \\
\hline Group II & HL & $3.47 \pm 0.40$ & $5.78 \pm 0.73$ \\
\hline Group III & HL+10P & $3.23 \pm 0.31 \mathrm{NS}$ & $6.67 \pm 0.79 \mathrm{NS}$ \\
\hline Group IV & HL+30P & $2.10 \pm 0.51^{*}$ & $6.37 \pm 0.54 \mathrm{NS}$ \\
\hline
\end{tabular}

(All values are Mean \pm Standard Deviation). $\mathrm{HL}=$ Hyperlipidemic group, $\mathrm{HL}+10 \mathrm{P}=$ Hyperlipidemic $+10 \mathrm{mg} / \mathrm{kg}$ Pioglitazone, $\mathrm{HL}+30 \mathrm{P}=$ Hyperlipidemic $+30 \mathrm{mg} / \mathrm{kg}$ Pioglitazone, MDA = Malondialdehyde, $\mathrm{SOD}=$ Superoxide dismutase. NS $=$ Non significant compared to Group II, $* p<0.05$ compared to Group II (ANOVA followed by Dunnett's test).

The lipid peroxidation product, malondialdehyde, in serum decreased in PIO treated groups as compared to hyperlipidemic group (i.e. from $3.47 \pm 0.40 \mathrm{nmol} / \mathrm{ml}$ to $3.23 \pm 0.31 \mathrm{nmol} / \mathrm{ml}$ and from $3.47 \pm 0.40 \mathrm{nmol} / \mathrm{ml}$ to $2.10 \pm 0.51 \mathrm{nmol} / \mathrm{ml}$ ) in $10 \mathrm{mg} / \mathrm{kg}$ and $30 \mathrm{mg} / \mathrm{kg}$ PIO treated groups, respectively (Table 4$)$. But the reduction of only $30 \mathrm{mg} / \mathrm{kg}$ PIO treated group was significant $(p<0.05)$.

The activity of superoxide dismutase increased in both experimental PIO treated groups as compared to hyperlipidemic group i.e. from $5.78 \pm 0.73 \mathrm{U} / \mathrm{ml}$ to $6.67 \pm 0.79 \mathrm{U} / \mathrm{ml}$ and from $5.78 \pm 0.73 \mathrm{U} / \mathrm{ml}$ to $6.37 \pm 0.54$ $\mathrm{U} / \mathrm{ml}$, respectively, in group III and IV (Table 4). These increases in superoxide dismutase activity were not statistically significant $(p=0.1115)$.

\section{DISCUSSION}

Diabetes mellitus (DM) is an endocrine disorder characterized by hyperglycemia, leading to disturbance in carbohydrate, lipid and protein metabolism. ${ }^{2}$ Insulin resistance is an important characteristic feature of type-2 diabetes and is commonly associated with the abnormalities in circulating lipids and lipoproteins that are considered to be important risk factors for atherosclerosis in diabetic individuals. Correction of these abnormalities may reduce the accelerated atherosclerosis and the related complications in diabetic patients. There is also increasing evidence that most of the complications related to diabetes are associated with oxidative stress, induced by the generation of free radicals. ${ }^{3}$ Therefore, treatment compounds with both lipid lowering and antioxidant properties would be useful as anti-diabetic agents.

Therefore, the present study was conducted to assess the hypolipidemic and antioxidant activities of PIO, one of the novel anti-diabetic medications, in hyperlipidemic rats. The lipid-lowering effects of PIO in hyperlipidemic rats, demonstrated in the present investigation, were related primarily to a decreased levels of total serum triglycerides and VLDL-cholesterol while increase in HDL-cholesterol level. There was no significant decrease in serum cholesterol as well as LDL-cholesterol in both PIO treated groups (Group III and IV).

The impact of PIO on the lipid profile in diabetic patients is not clearly consistent. ${ }^{4-7}$ PIO increases adipocyte differentiation and stimulates the distribution of new adipose tissue to both retroperitoneal and subcutaneous sites by activation of PPAR $\gamma$ receptors. ${ }^{4}$ Most studies show that PIO have an overall beneficial effect since PIO was found to increase HDL-C and lowered plasma TG and VLDL. Rosenblatt et $\mathrm{al}^{6}$ studied the impact of pioglitazone on glycemic control and atherogenic dyslipidemia in patients with type 2 diabetes mellitus. The study demonstrated that there were significant changes in triglycerides and HDL whereas the levels of total cholesterol and LDL were found to be nonsignificant. However, negative effects with PIO therapy such as increase in cholesterol and LDL levels have also been reported. In one study, by Hirose $\mathrm{H}$ et $\mathrm{al}^{7}{ }^{7} \mathrm{TG}$ and HDL remained unaffected and cholesterol and LDL levels increased significantly by administration of PIO. Because of these inconsistent effects of PIO on lipid profile, this study was undertaken.

Elevated levels of triglycerides are associated with atherosclerosis, even in the absence of hypercholesterolemia, and predispose to cardiovascular disease. ${ }^{18}$ High level of HDL-C is associated with fewer problems with cardiovascular diseases and vice versa. It is also well known that an increase in HDL-C level could potentially contribute to reversal of atherogenesis. This is because high level of HDL-C protects endothelial cells from the cytotoxic effects of oxidized LDL. ${ }^{19}$ In the present study, a significant lowering of plasma TG level with simultaneous increase in plasma HDL-C definitely indicate the beneficial role of PIO administration to hyperlipidemic animals.

The importance of the reactive oxygen species (ROS) has attracted increasing attention over the last decade. ROS includes free radicals, non free radicals and various forms of activated oxygen. They are involved in various physicochemical processes and pathogenesis of various 
serious diseases such as neurodegenerative disorders, cancer, cardiovascular diseases, atherosclerosis, cataracts and inflammation. ${ }^{20}$ Drugs with multiple protective mechanisms, including antioxidant activity, may be one way of minimizing complications of such type of diseases.

Presently noted lower levels of MDA and higher levels of catalase enzyme activities in PIO treated groups (mainly Group IV) indicate the possible role of PIO as antioxidants. Antioxidant activity of pioglitazone in diabetic patients is reported to be mediated by blocking the vicious cycle of ROS production, improve insulin sensitivity and halt the pro-inflammatory signaling transduction. ${ }^{21}$ In past, many studies were conducted with PIO to confirm its antioxidant activity., ${ }^{41-23}$ Taken together, these observations indicate that PIO administration to hyperlipidemic animals can reduce serum TG and increase serum HDL-C levels and also improve antioxidant enzyme activities.

\section{CONCLUSION}

Thus, we conclude that PIO could improve lipid profile and decrease oxidative stress in hyperlipidemic conditions which suggest that PIO may reduce cardiovascular risk by its hypolipidemic and antioxidant actions in patients with type 2 diabetes, especially when it is associated with increased triglyceride level.

\section{ACKNOWLEDGEMENT}

Authors are thankful to Dr. V. V. Wase, Dean, S. R. T. R. Govt. Medical College, Ambajogai, for allowing us to carry out this study.

\section{Funding: No funding sources}

Competing interests: None declared

Ethical approval: The study was approved by the

Institutional Animal Ethical Committee

\section{REFERENCES}

1. Pandey A, Tripathi P, Pandey R, Srivatava R, Goswami S. Alternative therapies useful in the management of diabetes: A systematic review. J Pharm Bioallied Sci 2011;3:504-12.

2. Mazumder PM, Farswan M, Parcha V. Effect of an isolated active compound $(\mathrm{Cg}-1)$ of Cassia glauca leaf on blood glucose, lipid profile, and atherogenic index in diabetic rats. Indian J Pharmacol 2009;41:182-6.

3. Shanmugam KR, Mallikarjuna K, Reddy KS. Effect of alcohol on blood glucose and antioxidant enzymes in the liver and kidney of diabetic rats. Indian $\mathbf{J}$ Pharmacol 2011;43:330-5.

4. Biswas A, Rabbani SI, Devi K. Influence of pioglitazone on experimental heart failure and hyperlipidemia in rats. Indian $\mathrm{J}$ Pharmacol 2012;44:333-9.
5. Kakadiya J, Shah NJ. Hypoglycemic and hypolipidemic activity of Pioglitazone in normal and Streptozotocin-Nicotinamide induced diabetic rats. Pharmacologyonline 2010;1:1-7.

6. Rosenblatt S, Miskin B, Glazer NB, Prince MJ, Robertson KE; Pioglitazone 026 Study Group. The impact of pioglitazone on glycemic control and atherogenic dyslipidemia in patients with type 2 diabetes mellitus. Coron Artery Dis 2001;12:413-23.

7. Hirose H, Kawai T, Yamamoto $\mathrm{Y}$, Taniyama M, Tomita M, Matsubara K et al. Effects of pioglitazone on metabolic parameters, body fat distribution, and serum adiponectin levels in Japanese male patients with type 2 diabetes. Metabolism 2002;51:314-7.

8. Visavadiya NP, R.L. Narasimhacharya AV. Hypolipidemic and antioxidant activities of Asparagus racemosus in hypercholesteremic rats. Indian J Pharmacol 2005;37:376-80.

9. Roeschlau P, Bernt E, Gruber F. J Clin Chem Clin Biochem 1974;12:226.

10. McGowan MW, et al. A peroxidase-coupled method for the colorimetric determination of serum triglycerides. Clin Chem 1983;29:538.

11. Lorentz K, Flatter B, Augustin E. Arylesterase in serum: elaboration and clinical application of a fixedincubation method. Clin Chem 1979;25:1714-20.

12. Chatterjee MN. Textbook of Medical Biochemistry, 7th edition. JAYPEE Brothers: New Deli, India 2007;418-20.

13. Schaffert RR, Kingsley GR. A rapid, simple method for the determination of reduced, dehydro-, and total ascorbic acid in biological membrane. $\mathrm{J}$ Bio Chem1955;212:59-68.

14. Cohen G. Dembiec D. Marcus J. Measurement of catalase activity in tissue extract. Anal Biochem1970;34:30-8.

15. Pasha KV, Sadasivadu B. Intracellular content of thiol compounds, thiobarbituric acid reactive substances and gamma-glutamyl transpeptidase in rat brain during anoxia. Neurosci Lett 1984;46:209-14.

16. Marklund S, Marklund G. Involvement of the superoxide anion radical in the autoxidation of pyrogallol and a convenient assay for superoxide dismutase. Eur J Biochem 1974;47:469-74.

17. Mahajan BK. Significance of difference in mean. In Methods in Biostatistics, 6th edition; 2006:130-55.

18. Durrington P. Dyslipidaemia. Lancet 2003;362:71731.

19. Assmann G, Nofer JR. Atheroprotective effects of high-density lipoproteins. Annu Rev Med 2003;54:321-41.

20. Singh R, Singh N, Saini BS, Rao HS. In vitro antioxidant activity of pet ether extract of black pepper. Indian J Pharmacol 2008;40:147-51.

21. Hsiao PJ, Hsieh TJ, Kuo KK, Hung WW, Tsai KB, et al. Pioglitazone retrieves hepatic antioxidant DNA repair in a mice model of high fat diet. BMC Mol Biol 2008;9:82.

22. Rabbani SI, Devi K, Khanam S. Pioglitazone, a PPAR-gamma ligand inhibited the nicotinamide- 
streptozotocin induced sperm abnormalities in type-2 diabetic Wistar rats. Pak J Pharm Sci 2010;23:326-31.

23. Hasegawa T, Okada K, Okita Y, Pinsky DJ. Antioxidant properties of pioglitazone limit nicotinamide adenine dinucleotide phosphate hydrogen oxidase and augment superoxide dismutase activity in cardiac allotransplantation. J Heart Lung Transplant 2011;30:1186-96.

doi: 10.5455/2319-2003.ijbcp20130115

Cite this article as: Bhosale RR, Jadhav RR, Padwal SL, Deshmukh VS. Hypolipidemic and antioxidant activities of pioglitazone in hyperlipidemic rats. Int $\mathbf{J}$ Basic Clin Pharmacol 2013;2:77-82. 